\title{
Heterogeneous Supported Catalysts for Butadiene Polymerization: The Effect of Calcination Temperature and Solvent
}

\author{
S. Tajammul Hussain ${ }^{*}, 1$, Rafia Naheed ${ }^{2}$, Amin Badshah ${ }^{2}$, M. Saddique $^{2}$, M. Saleem Khalid ${ }^{3}$ and \\ Zafar Iqbal Baig ${ }^{3}$
}

${ }^{I}$ National Centre for Physics, Quaid-i-Azam University, Islamabad, Pakistan

${ }^{2}$ Department of Chemistry, Quaid-i-Azam University, Islamabad, Pakistan

${ }^{3}$ National Engineering Scientific Commission, P.O. Box No. 2801, Islamabad, Pakistan

\begin{abstract}
The polymerization of butadiene was studied using heterogeneous cobalt nickel (oxide) bimetallic catalyst. The prepared catalyst was subjected to calcination at different temperatures. This treatment results in the formation of different phases with multiple oxidation states. The characterization of the catalyst was carried out by XRD, SEM, EDX, TGA, FTIR and TPR/TPD. The catalytic activity was studied for the polymerization of butadiene gas in toluene, n-hexane and ethanol in a Parr reactor system. The products obtained, were characterized by FTIR, GC/MS, ${ }^{1} \mathrm{H}$ and ${ }_{13} \mathrm{C}$ NMR spectroscopy, Laser Light Scattering (LLS) and GPC.

The best activity was achieved on the catalyst sample calcined at $1173 \mathrm{~K}$ in ethanol solvent. The product contains aliphatic and aromatic carbonyl compounds and polybutadiene terminated by OH group. The GPC and LLS studies indicates that polydispersity of the products are in the narrow range and high molecular weight product.
\end{abstract}

The study reflects that the catalytic reaction conditions, the calcinations temperatures which control the oxidation state, phase of the catalyst and stability of the catalyst are mainly responsible for the change in products selectivity.

Keywords: Heterogeneous catalysts, bimetallic, butadiene polymerization, calcination, solvents, aliphatic, aromatic products.

\section{INTRODUCTION}

Poly-butadiene (BR) is the second largest volume synthetic rubber produced next to styrene butadiene rubber (SBR). The major use of BR is in the tires with over $70 \%$ of the polymer produced into treads and side walls. For many polymerization systems, factors that influences the activity/selectivity and conversion of the working catalyst and then the product selectivity have been discussed and revealed that it is the double bonds of butadiene that are key to the polymer formation $[1,2]$.

The butadiene chain attached with the catalyst results in breaking the bond producing a chain growth intermediate which adds to give a long chain polymer product. Keeping into consideration the end product chemistry, the chain is terminated by the addition of $\mathrm{OH}$ group containing solvent to accomplish the required goals. Naturally the molecular characteristics directly influence exploitation properties of these polymers. The above mentioned items also relates to the stereo specific polymerization of dienes in the presence of the catalyst complex (a homogeneous catalyst). Modern theories concerning the mechanism of polymerization on Ziegler Natta catalyst explain many effective relationships between catalyst structure, temperature, reagent concentration, catalyst active metal ingredients and the

*Address correspondence to this author at the National Centre for Physics, Quaid-i-Azam University, Islamabad, Pakistan;

E-mail:dr_tajammul@yahoo.ca reaction conditions (flow rate, pressure, time of reaction). These affect the polymerization product molecular weight and their chemistry $[3,4]$.

To date the catalyst used for the polymerization of butadiene are comprised of an organo-cobalt compound, and organo aluminum compound. It must be noted here that inspite of many workers devoted to Butadiene Polymerization; there are not enough quantitative data in the literature on the influence of catalyst preparation conditions on its activity and stereo specificity and also on the molecular characteristics of the product formed.

The solution polymerization of butadiene is usually carried out in hydrocarbon solvents n - Hexane, Cyclohexane and Pentane. These are the most commonly used solvents, the advantage of aliphatic solvents over aromatic solvents are in lower price and lower toxicity. Aliphatic solvents are also superior in the final steps of the industrial process. In contrast to aromatic solvents, aliphatic and cycloaliphatic solvents are considered to be inert [5]. The use of aromatic solvents results in reduced catalyst activities as already reported by Taube and Sylvester [6]. Another common finding of various studies on the influence of solvent is the decrease of cis- 1, - 4 contents by the use of aromatic solvent $[7,8]$. In addition to aliphatic and aromatic hydrocarbons, chlorinated aliphatic hydrocarbons and ethers were tested in $\mathrm{Nd}$ catalyzed butadiene polymerization. Chlorinated aliphatic hydrocarbons strongly decrease catalyst activity and often yield insoluble polymer gel [9]. Ethers such as THF are catalyst poison. 
A series of comparative studies is available in which $\mathrm{Nd}$ based catalyst systems were tested in various solvents. Hsieh et al. studied the influence of cyclohexane, n-hexane, npentane, chlorinated arenas, toluene, 1 -hexane, tetrachloroethylene, and styrene in diene polymerization with the binary system $\mathrm{NdX}_{3} . \mathrm{nD} / \mathrm{AIR}_{3}$ [10]. Duvakina et al. investigated the influence of cholorobenzene, toluene, and cyclohexane on trans-1-4 content. In this study, the binary trans-1,4-specific catalyst system $\mathrm{NdCL}_{3}, \mathrm{TBP} / \mathrm{Mg}\left({ }^{\mathrm{n}} \mathrm{C} 4 \mathrm{H}_{9}\right)$ (iC8H17) was used [11]. For binary $\mathrm{Nd}$ (OiPr) 3 containing catalyst systems, the influence of the solvent heptane, cyclohexane, toluene, dichloromethane was investigated by Dong et al. [12,13]. Information about the influence of solvents on ternary $\mathrm{Nd}$ systems are available for $\mathrm{Nd}\left(\mathrm{N}\left(\mathrm{SiM}_{33}\right)_{2}\right)_{3} / \mathrm{TIBA} / \mathrm{DEAC}[7,8], \mathrm{NdV} / \mathrm{DIBAH} /{ }^{\dagger} \mathrm{BuCl}$ [14] $\mathrm{Nd}\left(\mathrm{O}^{\mathrm{i}} \mathrm{Pr}\right)_{3} /[\mathrm{HNMe} 2 \mathrm{Ph}]^{+}\left[\mathrm{B}\left(\mathrm{C}_{6} \mathrm{~F}_{5}\right)_{4}\right]^{-} / \mathrm{TIBA}$ [15] and $\mathrm{NdV} /$ methyl aluminoxane $(\mathrm{MAO}) /{ }^{\dagger} \mathrm{BuCl}[9]$.

One of the most detailed studies on the influence of solvents is available from Porri et al. [16, 17]. In these studies, the $\mathrm{Nd}$ carboxylate based systems $\mathrm{Nd}$ (isoctanoate) $3 /$ TIBA/DEAC was used. Porri et al. gives the following ranking of the solvents studied: cis-butene $>1$ pentene $>$ heptane $>(+3 \%$ toluene $)>$ toluene $>$ mesitylene $>$ toluene $(+7 \%$ hexamethylbenzene). The reduction of polymerization rates by aromatics solvents or by the presence of small amounts of aromatic compounds is explained by competitive coordination of monomer and arenas to vacant $\mathrm{Nd}$-sites.

In olefin polymerization, among the best catalysts for the tailoring of the properties of polyolefins are metallocenes. Although metallocene complex can be used in homogeneous form, they are often used in heterogeneous one, i.e. they are supported on an insoluble carrier prior to polymerization, typical support material are silica and alumina, magnesium chloride, zeolites, clays, micelles [18,19]. The reasons for the heterogeneous of the metallocene are, for example, slower deactivation of the metallocene, avoidance of reactor fouling, less co-catalyst required, good and uniform polymer morphology, higher polymer density and requirement of the commercial polymerization processes [20].

Methods for heterogenization of the metallocene complex to the support are often divided into three groups.

i. Direct immobilization of the metallocene on the support. Immobilization on the support pretreated with methylaluminoxane [MAO] [21,22].

ii. Alkylaluminium $[23,24]$ and activation of metallocene with aluminoxane prior to immobilization [18,20,25].

To-date the pioneering researches have been making extensive studies in the field of supporting single site catalyst on different supports like $\mathrm{MgCl}_{2}$ etc. [26].

Hetregeneous catalysts consisting of metals or metal oxides alone or adsorbed on the surface of solid supports are of commercial interest for low pressure polymerization of olefins [27]. Common catalyst composition includes oxides of chromium or molybdenum, cobalt and nickel metals, supported on silica, alumina, titania, zirconia or activated carbon [27]. The mechanism and kinetics of the mechanism are still largely unknown although many proposals like those made for Ziegler-Natta polymerization have been presented.

The system of Nickel and Cobalt bimetallic catalysts have been selcted for the following reasons.

1. Both $\mathrm{Ni}$ and $\mathrm{Co}$ exist in mixed valent states viz., $\mathbf{M}^{0}$ and $\mathrm{M}^{+2}$ even after catalyst reduction, in our case this is the key factor in the polymerization process.

2. After the adsorption of solvent the cobalt and nickel content increases on the surface many fold to that in the bulk. This also contributes towards the stability, activity and selectivity of the catalysts.

3. The increase in Cobalt and Nickel content on the surface indicates an increase in the amount of two metals which increases the adsorption and desorption rate of the solvent, as a result the enantioface differentiating ability of the catalyst decreases.

4. The electronic and stearic effects of the solvent over $\mathrm{Ni}$ :Co bimetallic surface results in the increase in ability to attract electron donating groups or electron attracting group.

To the best of our knowledge there are only few reports in the field of heterogeneous bimetallic catalyst systems having different oxidation states and phases used for polymerization studies. This study extensively reports the polymerization of Butadiene using heterogeneous metal catalysts coupled with the effect of different solvents and calcination temperature on the product selectivity.

We have found an interesting aspect from this study that by varying the reaction parameters and catalyst calcination temperature we can direct the polymerization products selectivity towards aliphatic/aromatic and trans or cis product formation. The kinetic parameters of the reaction are also studied and reported here. On the basis of our findings we postulated a mechanism for the formation of different molecular weight polymer products with very narrow polydispersity.

\section{EXPERIMENTAL}

\section{Materials}

$\mathrm{Co}\left(\mathrm{NO}_{3}\right)_{2} .6 \mathrm{H}_{2} \mathrm{O}$ purity of $>99 \%$ of FLUKA, $\mathrm{Ni}\left(\mathrm{NO}_{3}\right)_{2} .6 \mathrm{H}_{2} \mathrm{O}$ Purity of $>98 \%$ of FLUKA, Citric Acid Purity of $>99.5 \%$ used as a reducing agent. Ammonium hydoroxide $\left(\mathrm{NH}_{4} \mathrm{OH}\right)$ (35\% of Merk) was used to enhance the adsorption of metal on solid support. Freshly dried Toluene of Merk, n-Hexane Analytical Grade of Merk and absolute Ethanol along with Butadiene gas of purity of $99.999 \%$ were used in the study.

\section{Catalyst Preparation}

The catalysts were prepared using citrate route of sole gel. Citric acid was used as a reducing agent and ethanol as a solvent. Cobalt, Nickel nitrate and citric acid mole ratio of 1: 4 in $80 \mathrm{ml}$ ethanol was mixed for 30 minutes at $353 \mathrm{~K}$. The resulting slurry was dried at $473 \mathrm{~K}$ for 2 hours. The resulting solid was divided into three portions and calcined at $673 \mathrm{~K}$, $873 \mathrm{~K}$ and $1173 \mathrm{~K}$ for 6-hours to obtain different oxidation states of Cobalt/Nickel oxide bimetallic catalyst. 
Table 1a. Preparatory Variables and EDX Analysis

\begin{tabular}{|c|c|c|c|c|c|c|}
\hline $\begin{array}{c}\text { Catalyst } \\
\text { Designation }\end{array}$ & $\begin{array}{c}\text { Amount of } \\
\text { Cobalt Salt }\end{array}$ & $\begin{array}{c}\text { Amount of } \\
\text { Nickel Salt }\end{array}$ & Citric Acid & \% Co & \% Ni & \% O2 \\
\hline \hline Ni:CO $(\mathrm{Ox})$ & $3 \mathrm{gms}$ & $3 \mathrm{gms}$ & $10 \mathrm{gms}$ & 37.0 & 38.0 & 25.0 \\
\hline
\end{tabular}

Table 1b. Particle Size Calculated from Scherer Equation, Specific Surface Area and BET

\begin{tabular}{|c|c|c|c|c|c|c|c|c|c|}
\hline \multirow{2}{*}{$\begin{array}{c}\text { Catalyst } \\
\text { Designation }\end{array}$} & \multicolumn{3}{|c|}{ Particle Size (nm) } & \multicolumn{3}{c|}{ Specific Surface Area } & \multicolumn{3}{c|}{ BET Surface Area } \\
\cline { 2 - 10 } & $\mathbf{6 7 3 ~ K}$ & $\mathbf{8 7 3} \mathbf{~ K}$ & $\mathbf{1 1 7 3} \mathbf{~ K}$ & $\mathbf{6 7 3} \mathbf{K}$ & $\mathbf{8 7 3 ~ K}$ & $\mathbf{1 1 7 3} \mathbf{~ K}$ & $\mathbf{6 7 3 ~ K}$ & $\mathbf{8 7 3} \mathbf{K}$ & $\mathbf{1 1 7 3} \mathbf{~ K}$ \\
\hline \hline $\mathrm{Ni}: \mathrm{Co}\left(\mathrm{O}_{\mathrm{x}}\right)$ & 146 & 152 & 160 & 1.21 & 0.99 & 0.95 & 31 & 26 & 20 \\
\hline
\end{tabular}

The preparatory variables, catalyst compositions and EXD analysis of the prepared samples are presented in Table $\mathbf{1 a}$ and Table $\mathbf{1 b}$.

\section{THE CATALYST CHARACTERIZATION}

The morphologies of the support, the synthesized catalysts were examined by Phillips scanning electron microscope (SEM) XL-30ESEM FEG, equipped with an energy dispersive X-ray spectrometer (EDX). The samples were prepared according to the procedure reported in reference [28]. XRD (Phillips PW 3040/60 X Pert Pro) powder diffractometer was used for analysis, using nickel filtered copper $\mathrm{K}$ alpha radiations with generator setting of $40 \mathrm{KeV}$. The diffraction pattern were recorded in the range, $50 \sim 70^{\circ}$. The peak identification was accomplished in comparison with ASTM standard diffraction data file. BET surface area of all the samples were determined by nitrogen physisorption using a Micromeretics ASAP 2010. The samples were degassed at $155^{\circ} \mathrm{C}$ for 3-hours before the experiment. The thermal decomposition behavior of the samples were studied by Thermogravimetric analysis (TGA), and differential thermal analysis (DTA) on a Mettler TGA/SDTA 851 in oxygen environment. Temperatureprogrammed reduction (TPR) studies were carried out with TPDRO 1100 Series Thermo Electron Corporation system. The accuracy was $\pm 5{ }^{\circ} \mathrm{C}$. The Infrared (IR) spectra of the catalysts and product were obtained on Bio-Red Excalibur FTIR Model $3000 \mathrm{MX}$ as $\mathrm{KBr}$ pellet and as $\mathrm{NaCl}$ cell respectively. The $1 \mathrm{H}$ and ${ }^{13} \mathrm{C}$-NMR spectra of polymer were recorded on a Bruker $300 \mathrm{MHz}$ instrument, using deturated chloroform CD3OD as solvent. The GPC analysis were performed using Perkinelmer Injector Detector L3350 equipped with RI Monitor. All the samples were referenced to standard.

Laser Light Scattering (LLS) of the products were performed using a commercial light-scattering spectrometer (ALV/SP- 150 equipped with an ALV-5000 multi-ô digital time correlator) was used with a solid-state laser (ADLAS DPY 425II, output power $400 \mathrm{~mW}$ at $\ddot{e}=532 \mathrm{~nm}$ ) as light source. For each sample four concentrations ranged from $2.0 \mathrm{x}$ $10^{-3}$ to $8.00 \times 10^{-3} \mathrm{~g} / \mathrm{mL}$ were prepared by dilution. All polymer solutions were filtered by using a $0.50-\mu \mathrm{m}$ Whatman filter in order to remove dust completely.

Analysis of the exit gasses and oily samples were carried out using on line GC/MS 6890N Egilent Technology USA.
The poropak Q column was used for GC analysis. Before the analysis the GC was calibrated using standard mixtures of hydrocarbons aliphatic/aromatics products supplied by BOC, UK.

\section{BUTADIENE POLYMERIZATION}

For each experiment 2.5 gms of catalyst was loaded inside the SS microreactor (Fig. 1) using ethanol, n-hexane and toluene in three different experiments with catalyst samples calcined at $673 \mathrm{~K}, 873 \mathrm{~K}$ and $1173 \mathrm{~K}$. The system was flushed with argon to ensure complete removal of air from the microreactor and then butadiene at 50 60 psig pressure at a flow rate of $40-50 \mathrm{mls} / \mathrm{min}$ was injected into the microreactor with continuous stirring. The temperature of the reaction was raised to $130{ }^{\circ} \mathrm{C}$ in increment of $5{ }^{\circ} \mathrm{C}$. The reaction temperature was maintained at $130{ }^{\circ} \mathrm{C}$ for $2 \mathrm{hrs}$. The catalytic reaction was monitored with continuous injecting the sample in to on line GC/MS, when the product becomes stabilized the reaction was stopped and the resultant mixture was analyzed using ${ }^{1} \mathrm{H}-\mathrm{NMR}$ and ${ }^{13} \mathrm{CNMR}$ along with GC/MS, FTIR, GPC and LLS (Laser Light Scattering).

Blank experiments were also carried out and the product obtain was analyzed by $\mathrm{NMR}$ and GC/MS but no appreciable peak was obtain.

\section{RESULTS AND DISCUSSIONS}

\section{Characterization of Catalysts}

SEM micrographs of the samples calcined at different temperatures are presented in Fig. (2a, c, e, Fresh Catalysts). No open pore structures can be seen on Fresh the samples calcined at $673 \mathrm{~K}$ and $873 \mathrm{~K}$. The sample which was calcined at $1173 \mathrm{~K}$ irregular pore structure can be seen. The packing order seen on these samples could be due to geometrically well defined channels of the oxide formed and such structures are fairly stable. The SEM analysis performed on the spent catalysts (Fig. 2b, d, f) does support our argument, where the particle size, characteristics and the nature of the catalytic active sites changes appreciably.

The adsorption-desorption curve shown in the Fig. (3) support our argument presented above where the hysteresis structure of the catalysts reflects the formation of channeling within the sample pores, these channeling changes the adsorption and desorption chemistry of the catalyst during the polymerization reaction and consequently results in the 


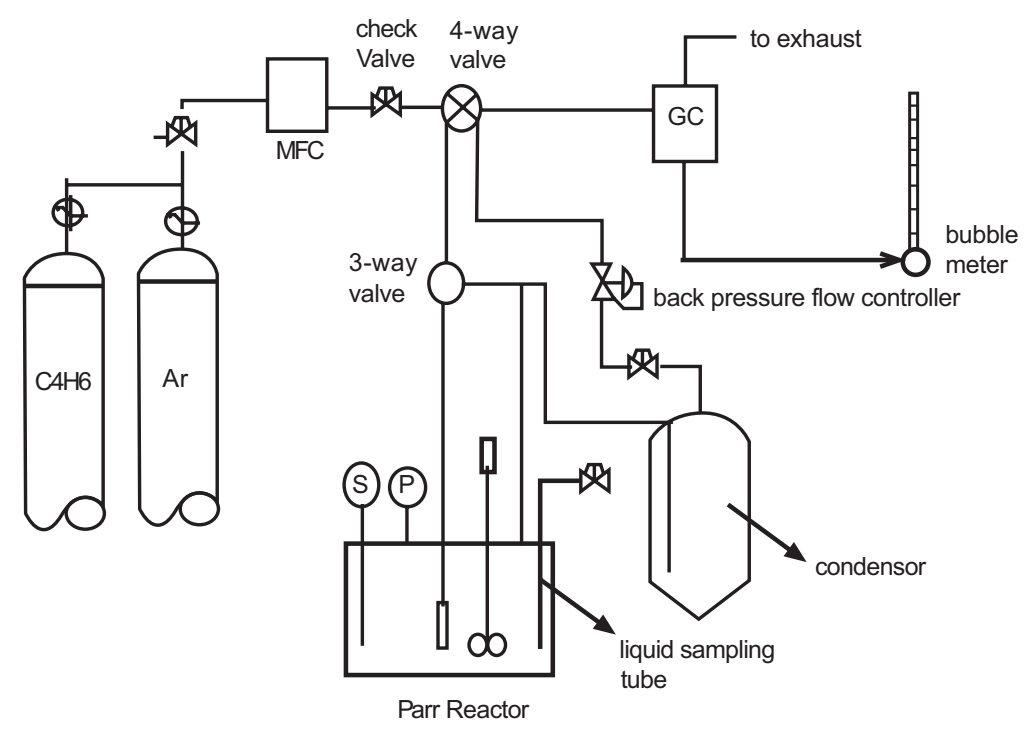

Fig. (1). Catalytic activity test system.

highest specific surface area and excellent polymerization properties.

(a)

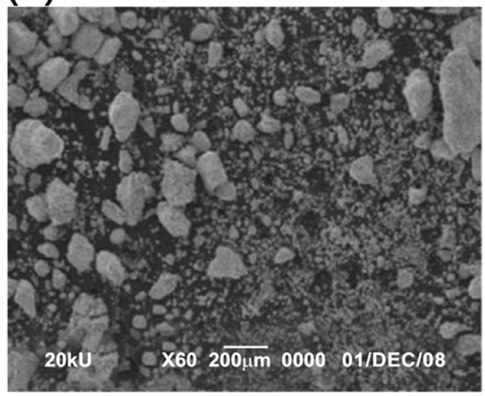

(c)

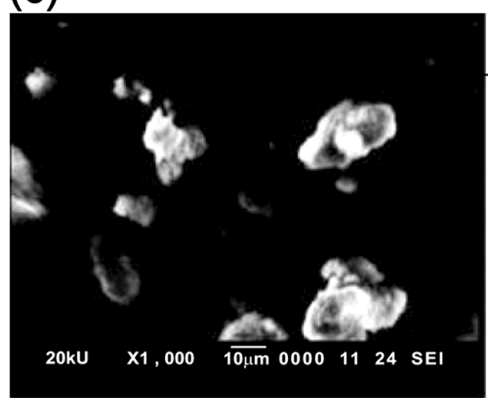

(e)

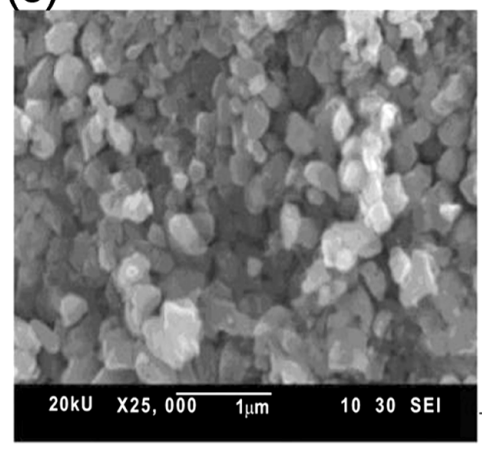

What we are proposing here, that as we increase the calcinations temperature the $\mathrm{Ni}$, Co particles shift to single (b)

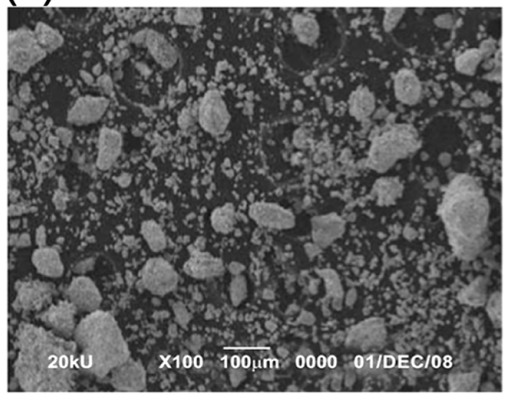

(d)

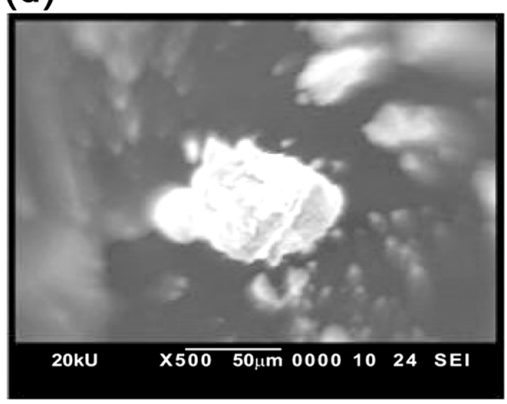

(f)

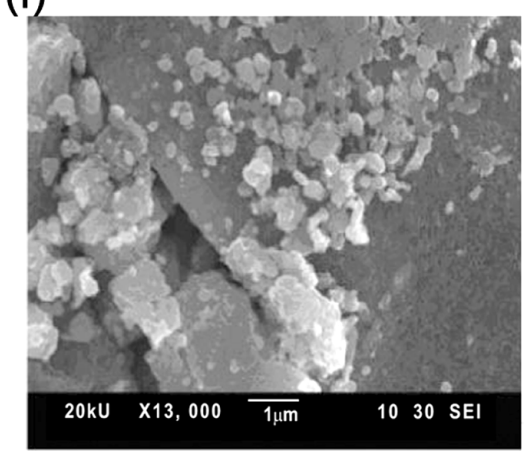

Fig. (2). SEM Analysis of the prepared catalyst system (a, c, e Fresh, calcined at $673 \mathrm{~K}, 873 \mathrm{~K}, 1173 \mathrm{~K}$ ), (b, d, f, spent calcined at $673 \mathrm{~K}$, $873 \mathrm{~K}, 1173 \mathrm{~K})$. 
oxidation states due to which the electronic interaction between two metals increases as our XPS/XRD data suggests. Consequently the adsorption capacity of the catalyst increases. This adsorption increase is related directly to the increase in pore volume, since at this temperature only metals with single oxidation states are available, this results increase in catalyst stability, activity and selectivity. Fig. (3) presents the adsorption desorption curves at three different temperature. The study of Fig. (3) revealed that adsorption intensity is considerably higher on the catalyst sample calcined at $1173 \mathrm{~K}$ and correspondingly desorption curve shows higher volume of desorption $\left(270 \mathrm{~cm}^{3} / \mathrm{gm}\right.$ at STP $)$ in comparison with catalyst calcined at 673 and $873 \mathrm{~K}$ which has 175 and $75 \mathrm{~cm}^{3} / \mathrm{gm}$ desorption at STP).

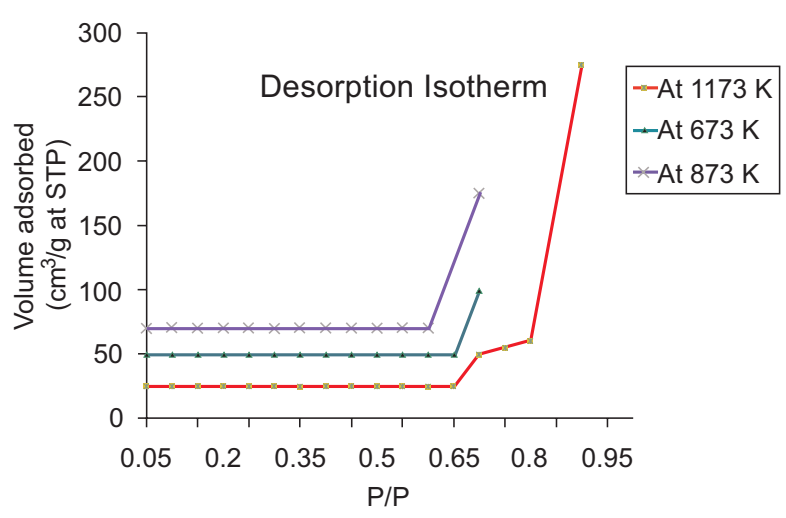

Fig. (3). Adsorption-Desorption Isotherm of sample ( $\mathrm{Ni}: \mathrm{Co}(\mathrm{Ox}))$.

\section{Catalyst Characterization Using XRD}

The XRD of the samples calcined at different temperatures are presented for fresh and spent catalysts in Fig. (4a, b). The study of the XRD data reveals crystalline characteristics of the catalyst samples calcined at 673 and $873 \mathrm{~K}$, because of narrower peak width in comparison of the sample calcined at $1173 \mathrm{~K}$. The particle size of the calcined and prepared catalyst samples are calculated from Scherer equation BET and specific metal surface area of the catalysts is calculated using procedures described in reference [29] are presented in Table 1b. Study of the peak intensity of the catalyst samples calcined at $1173 \mathrm{~K}$ indicates phase transition from octahedral $\mathrm{C}_{0304}$ to tetrahedral of $\mathrm{CoO}$ [30]. Where as only one phase of $\mathrm{Ni}$ and $\mathrm{Co}$ is seen on the samples calcined at 673 and $873 \mathrm{~K}$. The peak broadening and low intensity on the catalyst calcined at 673 and 873K, reflects the amorphous nature of the prepared system. The $1173 \mathrm{~K}$ calcined sample shows electronic interaction of $\mathrm{Ni}: \mathrm{Co}\left(\mathrm{O}_{\mathrm{x}}\right)$. The increase in particle size also confirms the high crystalline nature of the material. This is a direct indication of the effect of calcination temperature on the catalyst oxidation states. The reduction degree for the catalyst calcined at 673 , 873 and $1173 \mathrm{~K}$ at different reaction time were plotted and presented in (Fig. 5) is higher $(\alpha=0.73)$ on the sample calcined at $1173 \mathrm{~K}$ in comparison with the catalyst calcined at 673 and $873 \mathrm{~K}(\alpha=0.23$ and 0.27 respectively). This is an agreement with the diffusion problems observed by Serra et al. [31].

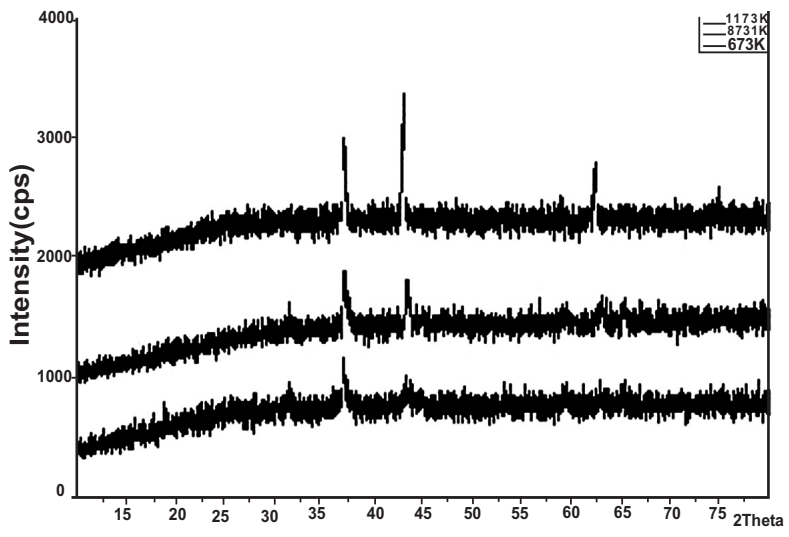

Fig. (4a). XRD analysis of the catalyst system (Fresh).

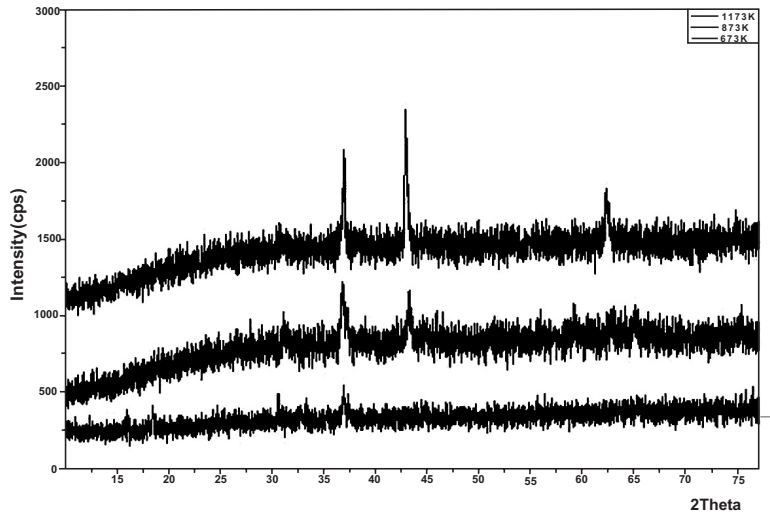

Fig. (4b). XRD analysis of the catalyst system (Spent).

\section{Catalysts Characterization Using TGA}

Thermodynamic parameters were calculated from TGA studies using the procedure described in reference $[47,48]$ and are presented in Table $\mathbf{2}$. The thermodynamic parameters suggest that the formation of $\mathrm{Ni}: \mathrm{Co}\left(\mathrm{O}_{\mathrm{x}}\right)$ bimetallic electronically modified geometry on the sample calcined at $1173 \mathrm{~K}$ in comparison with other catalysts because of the changes induced within the catalyst lattices as can be observed with the change in entropy, heat of reaction and activation energy (Table 2). These higher oxidation states of $\mathrm{Ni}: \mathrm{Co}\left(\mathrm{O}_{\mathrm{x}}\right)$ changes the reaction chemistry during the polymerization reaction. It produces an extra amount of energy because of higher oxidation states which results in increase in acidic nature of the active sites. This makes the reaction exothermic and its activation energy is decreased. This is a direct reflection of the presence of electronically modified active sites within the catalyst matrix, which results in increased catalyst activity, product selectivity and \% conversion. The EDX analysis presented in Table 1 reflects the changes in the reaction chemistry, where the Nickel and Cobalt concentration on this catalyst comes out to be $38 \%$ and $37 \%$ respectively, consequently the major contribution in the catalyst behavior comes from mixed $\mathrm{CoO}: \mathrm{Ni}(\mathrm{Ox})$ bimetallic phase, geometry, mechanical strength and particle shape. It is our observation that edges and corners of the catalyst particles have an important role to play during the polymerization process, where the adsorption/desorption 
Table 2. Thermodynamics Parameters Calculated from TGA Data

\begin{tabular}{|c|c|c|c|c|c|c|c|c|c|}
\hline \multirow{2}{*}{$\begin{array}{c}\text { Catalyst } \\
\text { Designation }\end{array}$} & \multicolumn{3}{|c|}{$\Delta \mathrm{S}($ Kcals $/ \mathrm{mol})$} & \multicolumn{3}{|c|}{$\Delta \mathrm{H}(\mathrm{Kcals} / \mathrm{mol})$} & \multicolumn{3}{|c|}{$\Delta \mathrm{Ea}($ Kcals/mol) } \\
\hline & $1173 \mathrm{~K}$ & $873 \mathrm{~K}$ & $673 \mathrm{~K}$ & $1173 \mathrm{~K}$ & $873 \mathrm{~K}$ & $673 \mathrm{~K}$ & $1173 \mathrm{~K}$ & $873 \mathrm{~K}$ & $673 \mathrm{~K}$ \\
\hline $\mathrm{Ni}: \mathrm{Co}(\mathrm{Ox})$ & -210.52 & -258.81 & -271.28 & 18.79 & 9.90 & 5.86 & 10.47 & 17.71 & 22.63 \\
\hline
\end{tabular}

$\Delta \mathrm{Ea}=$ Activation Energy of catalytic reaction.

$\Delta \mathrm{H}=$ Heat of reaction.

$\Delta \mathrm{S}=$ Disorder-ness of the catalytic reaction.

chemistry stoichiometery changes, resulting in the production of polymeric products.

\section{The TPD/R Study}

The Temperature Programmed Reduction/Desorption equipment is equipped with $273-1273 \mathrm{~K}$ programmable temperature furnace. Each sample $(50 \mathrm{mg})$ was first heated at $673 \mathrm{~K}$ in an argon flow $\left(8{ }^{\circ} \mathrm{Cm}^{3} / \mathrm{min}\right)$ for $3-4$ hours to remove all the surface impurities. The sample was then heated in a vol $\% \mathrm{H}_{2} / \mathrm{Ar}$ flow $\left(80 \mathrm{~cm}^{3} / \mathrm{min}\right)$ from $673 \mathrm{~K}$ to $1173 \mathrm{~K}$ at a rate of $5 \mathrm{~K}$ min- 1 and maintained at $1173 \mathrm{~K}$ until reduction process was finished. The TPD was performed in pure hydrogen with a flow rate of $\left(80 \mathrm{~cm}^{3} / \mathrm{min}\right)$. The temperature was raised to $673 \mathrm{~K}$ from room temperature at 1 $\mathrm{K} \mathrm{mn}^{-1}$ up to $673 \mathrm{~K}$. They were isothermally maintained at this temperature for 4-hours. The samples were than cooled to room temperature in the hydrogen flow, and heated at a rate of $10 \mathrm{~K} / \mathrm{min}$ to $1123 \mathrm{~K}$. The hydrogen desorption was detected with TCD detector. For the Hydrogen Chemisorption the samples were reduced under the same condition described above. After reduction, the chemisorbed hydrogen was removed in the stream of $30 \mathrm{ml} / \mathrm{min}$ of He for 30 minutes at $683 \mathrm{~K}$. The sample was subsequently cooled to $303 \mathrm{~K}$ in the He stream. The chemisorbed hydrogen was analyzed at $303 \mathrm{~K}$. The nickel and cobalt surface area was calculated assuming a stoichiometery of one hydrogen molecule per two surface atoms and an atomic cross sectional area of $6.49 \times 10^{-20} \mathrm{~m}^{2} / \mathrm{Ni}, \mathrm{Co}$ atoms. The reducibility of the sample $\mathrm{Ni}: \operatorname{Co}\left(\mathrm{O}_{\mathrm{x}}\right)$ the short listed best catalyst on the basis of polymeric activity was estimated by TPR, considering its initial reduction temperature obtained from the literature [32]. Our goal was to confirm the degree of reduction $(\alpha)$ observed by XRD on our catalysts. The results of the study is presented in Fig. (5). The initial reduction temperatures values are $515 \mathrm{~K}$ for sample calcined at $473 \mathrm{~K}, 708 \mathrm{~K}$ for sample calcined at $673 \mathrm{~K}, 876 \mathrm{~K}$ for sample calcined at $873 \mathrm{~K}$ and $1083 \mathrm{~K}$ for the sample calcined at $1173 \mathrm{~K}$. This confirms that the interaction between $\mathrm{NiO}: \mathrm{Co}(\mathrm{Ox})$ leads to the formation of bimetallic $\mathrm{NiO}: \mathrm{Co}(\mathrm{Ox})$ sites at lower temperature with different oxidation states. As the calcinations temperature increases up to $1173 \mathrm{~K}$, the multiple oxidation states are conversed to single bimetallic states. To obtain information about their active sites, temperature programmed desorption of hydrogen was performed on all the catalysts samples. The mechanism of adsorption/desorption of hydrogen are extremely complex [34, 35] especially when dealing with bimetallic catalyst systems. This is because phenomena related to the interaction between different active phases can interfere. TPD data shows two peaks on the sample calcined in between $473 \mathrm{~K}$ to $873 \mathrm{~K}$ one in the lower temperature region and the other at higher temperature region. For the catalyst calcined at $1173 \mathrm{~K}$ these two regions are merged into a single peak.

The low temperature TPD profile has been associated with different adsorption states of the hydrogen on bimetallic catalysts [33-35]. It is attributed to the occurrence of high temperature peaks to hydrogen spillover taking place during high temperature treatment of our catalysts. We also suggest here taking into consideration the discussions presented above that the high temperature peak is associated with other adsorption states of hydrogen (due to a difference in morphology and changes in particle size). Another point worth considering here that higher metallic area attained on the supported catalysts results in the lower adsorption peaks of hydrogen and especially due to the presence of specific active oxidation states induced in the system by different calcinations temperatures. This is the reason that the changes in catalytic activity/selectivity and product distribution, takes place on our system.

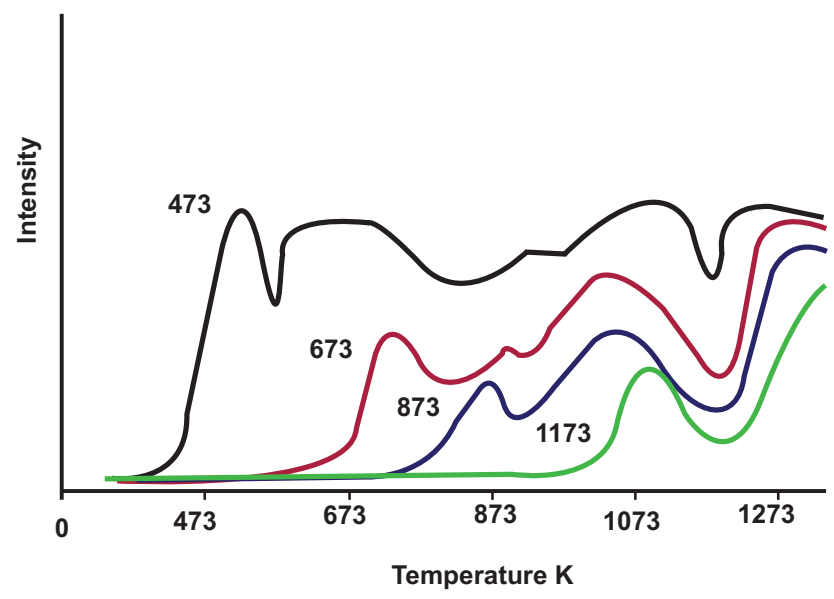

Fig. (5). TPR/D study of $\mathrm{Ni}: \mathrm{CO}\left(\mathrm{O}_{\mathrm{x}}\right)$ sample calcined at different temperatures.

The TPD of pyridine on the samples calcined at 673,873 and $1173 \mathrm{~K}$ presented in Fig. (6) suggest that as the calcinations temperature ingresses the catalyst geometry is shifted towards the single oxidation states thereby increasing no. of acid active sites available for the reaction in comparison with the catalyst calcined at 673 and $973 \mathrm{~K}$.

\section{The FTIR Studies}

The FTIR studies were performed on the sample calcined at $1173 \mathrm{~K}$ which shows best catalytic activity and polymeric selectivity presented in Table 3 and Fig. (7). On fresh and spent catalysts shows a sharp band at $1384 \mathrm{~cm}^{-1}$ and a broad band at $3456 \mathrm{~cm}^{-1}$. These bands are due to $\mathrm{CH}_{2} \mathrm{OH}$ as adsorbed species. The absorption band in range of $1647 \mathrm{~cm}^{-1}$ 
indicates the presence of $\mathrm{C}=\mathrm{C}$ group, the sharp and characteristic peak of carbonyl group $\mathrm{C}=\mathrm{O}$ is present at 1730 $\mathrm{cm}^{-1}$ The weak and medium intensity of C-O-C is present in the range of $1110 \mathrm{~cm}^{-1}$, on the surface of spent catalyst. This indicates that whole polymerization process takes different interaction routes on different types of active sites due to different oxidation states and phases of $\mathrm{Ni}$ and $\mathrm{Co}$ as confirmed by TGA and XRD studies. The FTIR data of fresh (F)and spent $(\mathrm{S})$ catalyst before and after catalytic reaction is presented in Table 3, which support our findings.

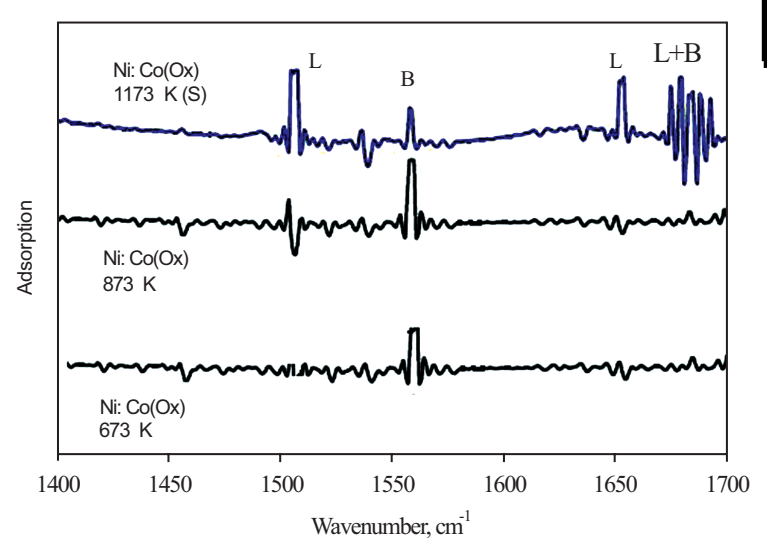

Fig. (6). TPD of Pyridine adsorption.

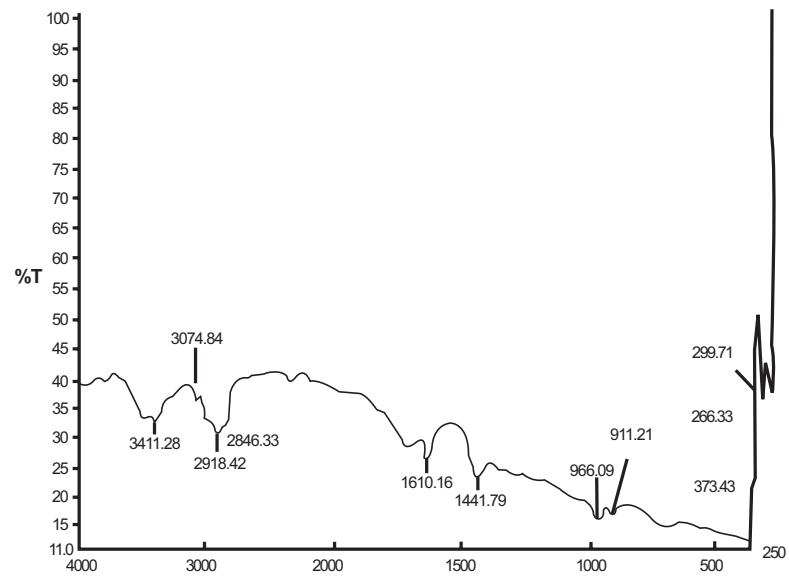

Fig. (7). FTIR spectra of the spent $\mathrm{Ni}: \mathrm{Co}\left(\mathrm{O}_{\mathrm{x}}\right)$ catalyst calcined at $1173 \mathrm{~K}$.

\section{The XPS Study}

The XPS study performed on the sample calcined at 1173 $\mathrm{K}$ and presented in Fig. (8) confirms the findings of $\mathrm{XRD} / \mathrm{SEM} / \mathrm{TPD} / \mathrm{R}$ that at $1173 \mathrm{~K}$ the electronic interaction between $\mathrm{Ni}$ and Co shift the binding energy towards positive side and indication of creation of ensemble effect, whereas no appreciable effect on the binding energy is observed on the samples calcined at $673 \mathrm{~K}$ and $873 \mathrm{~K}$.
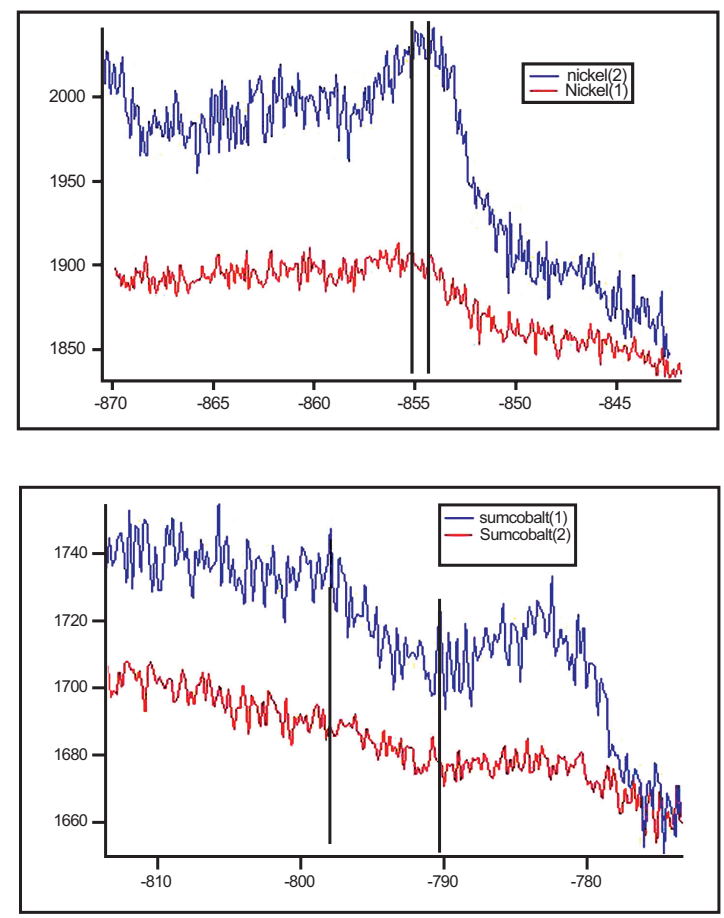

Fig. (8). XPS studies of the Fresh (1) and Spent (2) Ni:Co( $\left(\mathrm{O}_{\mathrm{x}}\right)$ catalyst sample.

\section{CATALYTIC ACTIVITY}

The conversion-time plot presented in Fig. (9a-c) for the polymerization process is transformed in to first order plots and presented in Fig. (10) reveals that polymerization rate decreases in order ethanol $>$ n-hexane $>$ toluene. The maximum conversion is achieved on the catalyst sample calcined at 1173 K, Fig. (9a). On the basis of the results presented in Fig. (6), a linear dependency is only obtained for the polymerization in ethanol. The respective first-order plots polymerization of $n$-hexane and toluene are curved. The deviation from the respective straight lines is more pronounced in $n$-hexane and in toluene. On the basis of this evidence only the polymerization in ethanol is in compliance with the first order requirement for a living polymerization $[32,36]$. Due to deviation from the first order dependencies, the polymerization in $n$-hexane and toluene do not comply with the requirement. The argument reported in References

Table 3. Interpretation of FTIR Spectra of the Fresh (F) and Spent (S) Catalysts

\begin{tabular}{|c|c|c|c|c|c|c|c|}
\hline Catalyst & C-O-C & $\begin{array}{c}\mathbf{O} \\
\text { C-C }\end{array}$ & $\begin{array}{c}\text { In plane } \\
\text { Pri-Alcoholic } \\
\mathbf{C - O H}\end{array}$ & $\begin{array}{c}\text { Second Ary- } \\
\mathbf{C H 2 O H}\end{array}$ & $\mathbf{C}=\mathbf{C}$ & $\mathbf{C = 0}$ & $-\mathbf{O H}$ \\
\hline \hline $\mathrm{Ni}: \mathrm{Co}(\mathrm{O} \mathrm{x})$ & --- & --- & --- & --- & --- & --- & - \\
\hline (F) & & & & & & & \\
\hline $\mathrm{Ni}: \mathrm{Co}(\mathrm{O} x))$ & 1110 & 1123 & 1274 & 1384 & 1647 & 1730 & 3456 \\
\hline$(\mathrm{S})$ & & & & & & & \\
\hline
\end{tabular}


$[32,36]$ it can be concluded that irreversible chain termination reactions occur in $\mathrm{n}$ - hexane and toluene.

The best selectivity achieved for ethanol solvent is due to its structure, it is easier to break $\mathrm{C}-\mathrm{H}$ bond in ethanol rather than in toluene and n-hexane. Our TGA data and the results reported in Fig. (5) supports this argument where the changes in kinetics and thermodynamics parameters reflect the linear chain solvent have higher adsorption and desorption rate an important aspect for catalysis reaction.

In order to quantitatively compare catalyst activities in ethanol, n-hexane and toluene, catalyst turn over frequencies (TOF) were calculated from the time conversion plots given in Fig. (5a-c). The following orders of TOF values were determined: $7620 \mathrm{~h}^{-1}$ for ethanol $>3452 \mathrm{~h}^{-1}$ for $\mathrm{n}$-hexane $>$ $1650 \mathrm{~h}^{-1}$ for toluene. From the ratios of TOF values the relative apparent concentration of active species can be estimated: for ethanol $>1$, for $n$-hexane $>0.21$, for toluene $>0.11$. The reduction of active $\mathrm{Ni}: \mathrm{Co}\left(\mathrm{O}_{\mathrm{x}}\right)$ sites in $n$-hexane and in toluene can be quantitatively explained on the basis of competitive coordination between butadiene and n-hexane and toluene solvents to active $\mathrm{Ni}: \mathrm{Co}\left(\mathrm{O}_{\mathrm{x}}\right)$ oxidation states which constitute active catalytic centers for this process. As n-hexane and toluene have more or less similar Lewis basicity, the lower polymerization activity in both cases is a hint of an additional reduction of active sites by irreversible chain termination.

The higher product selectivity achieved in case of ethanol could be ascribed due to the characteristic surface properties of the catalyst, leading to sufficiently coverage with weakly bound hydrogen which diverts the reaction towards the formation of aliphatic products at lower temperature. The catalyst calcined at higher temperature tilted more towards strongly bound hydrogen, thereby increasing the concentration of surface intermediates, thus producing aromatic hydrocarbons. At weakly bound hydrogen crystallization is not favored. On the other hand the strong bonded hydrogen increases the hydrogen/intermediate ratio and thus producing enough hydrogen enriched species to give the aromatic products. We also propose here at lower temperature the crystallinity of the catalyst particles also contribute towards the shift in product formation. The metal surface area availability could be another cause.

From the activity data we can also suggest that the temperature of calcinations of our catalyst system strongly influence the molecular weight distribution of the resultant polymers. When the catalyst is calcined at $673 \mathrm{~K}$ and $873 \mathrm{~K}$ respectively the resultant catalyst were found not significantly active for butadiene polymerization. On the contrary the catalyst pretreated at $1173 \mathrm{~K}$ was found active because of the uneven particles shape as can be seen in SEM study. A particularly important feature of heterogeneous catalyst in case of polymerization is its ability to give uneven particle size and geometry. As indicated in SEM study of the $\mathrm{Ni}: \mathrm{Co}\left(\mathrm{O}_{\mathrm{x}}\right)$ catalyst, calcined at $1173 \mathrm{~K}$ is the formation of channels and uneven surface, consequently the polymerization is taking place outside and inside of the catalyst almost simultaneously. In this way this catalyst is highly productive, good morphology and high bulk density. This argument confirms that, this type of catalyst morphology can be replicated throughout catalyst preparation and treatment. An important factor in the polymerization process is the particle size which generates extra amount of thermal energy during the polymerization process to proceed.

The carbon mass balance of the process was maintained during the catalytic polymerization studies. Conversion and selectivity were calculated using the following procedure.

Conversion (\%): [moles of 1,4 Butadiene consumed) $\mathrm{x}$ 100 [moles of 1.4 Butadiene charged] Activity (\%): [moles of one product of reaction] x 100/[moles of 1,4 Butadiene consumed]. The carbon mass balance of the process was also maintained.

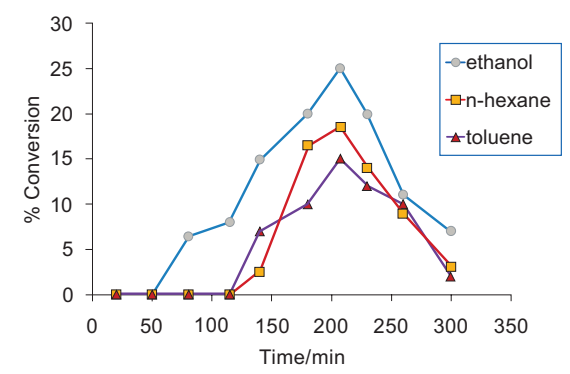

Fig. (9a). Conversion time plot of the catalyst $\mathrm{Ni}: \mathrm{Co}(\mathrm{Ox})$ calcined at $1173 \mathrm{~K}$.

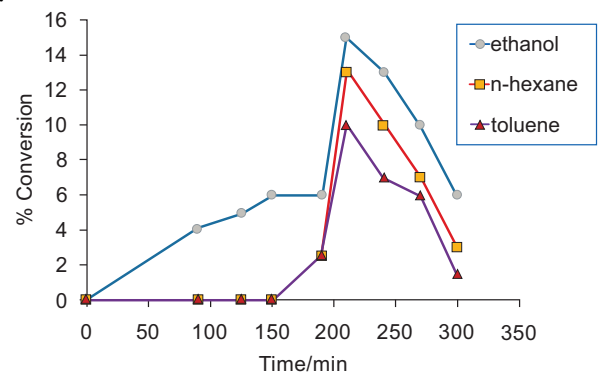

Fig. (9b). Conversion time plot of the catalyst $\mathrm{Ni}: \mathrm{Co}(\mathrm{Ox})$ calcined at $873 \mathrm{~K}$.

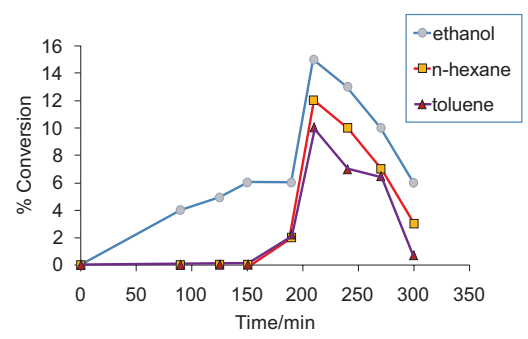

Fig. (9c). Conversion time plot of the catalyst $\mathrm{Ni}: \mathrm{Co}(\mathrm{Ox})$ calcined at $673 \mathrm{~K}$.

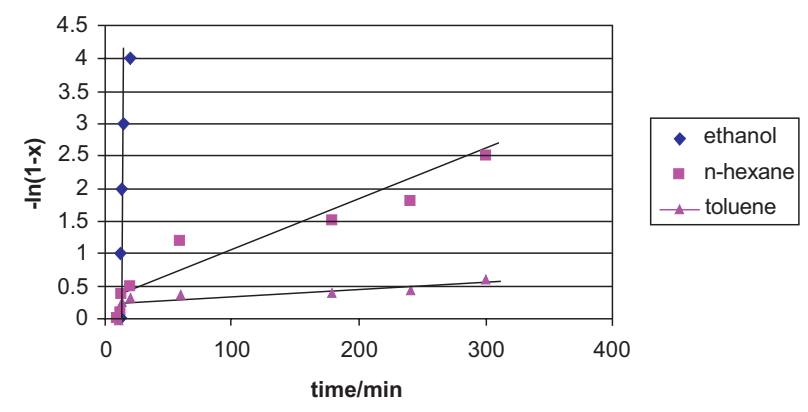

Fig. (10). The conversion time plot of figure $(5, a-c)$ is transferred into first order plots $[-\ln (1-\mathrm{x})$ vs time] for the catalyst $\mathrm{Ni}: \mathrm{Co}(\mathrm{Ox})$ caclined at 673,873 and $1173 \mathrm{~K}$. 


\section{CHARACTERIZATION OF PRODUCTS}

The microstructure of Butadiene Polymerization product was determined by IR spectroscopy (Figs. 11, 12). The following peaks were used for quantitative determination of polymer structure: $723 \sim 760 \mathrm{~cm}^{-1}$ is due to long chain band. The vinyl loop for ( $\sigma$ (cis-R=CR-) cis-1-4, $=0.192), 912$ $\mathrm{cm}^{-1}(\sigma(\mathrm{RCH}=\mathrm{CH}-\mathrm{H}), \mathrm{i} 1,2, \sim=1.0), 965 \mathrm{~cm}^{-1}$ ( $\sigma$ (trans-R$\mathrm{CH}=\mathrm{CR}-\mathrm{H}), \mathrm{I}$ trans-1, 4, 0.769). The aromatic absorption band is present in $1580 \sim 1600 \mathrm{~cm}^{-1}$. The polymeric $\mathrm{H}-$ bonding is found in $3400 \sim 3441 \mathrm{~cm}^{-1}$, the absorption at 3150 $\mathrm{cm}-1$ is due to stretching of $=\mathrm{C}-\mathrm{H}$. The characteristic carbonyl peak is present at $1730 \mathrm{~cm}^{-1}$ as shown in Fig. (8). The validity of the Lambert-Beer law was assumed.

Polybutadiene which are predominantly of 1,4 microstructure show two major signals of ${ }_{13} \mathrm{C}$ at $27.2 \sim 27.4$ and 32.5 32.7 ppm corresponding to cis and trans methylene carbons next to 1,4 units respectively. A high vinyl contents, a methylene carbon line at $30.97 \mathrm{ppm}$ has been assigned. The peaks assigned at $42.03 \sim 44.51 \mathrm{ppm}$ is for $1,4-\mathrm{v}-1,4 \mathrm{CH}$ [37]. When polymerization is carried out in ethanol solvent, we can get the microstructures of aliphatic and aromatic carbonyl compounds. Fig. (13) the signals at 167.8, 128.81, 130.9 and $132.43 \mathrm{ppm}$ of ${ }_{13} \mathrm{C}$ and $7.53,7.76 \mathrm{ppm}$ of ${ }_{1} \mathrm{H}$ are the specific signals of microstructure of pthalic anhydride [38] as shown in. The MS results presented in Table 4 shows $\mathrm{M}^{+}$with $100 \%$ relative abundance at $\mathrm{m} / \mathrm{z}=149$ and other decomposition and fragmentation pattern does support our argument Monomer conversion was determined gravimetrically. For this purpose, samples were taken and weighed (still containing solvent and monomer). The weight of the samples was determined again after polymerization had been short stopped with ethanol and after residual solvent has been removed by vacuum drying at $338 \mathrm{~K}$.

Kinetic parameters of polymerization were calculated from product molecular mass plotted $v s$ time of polymerization and monomer and catalyst concentration according to references [39-41].

The ${ }^{13} \mathrm{C},{ }_{1} \mathrm{H}$ - NMR and GC/MS data of the synthesized compounds showed that microstructures obtain were of three different types:
1.

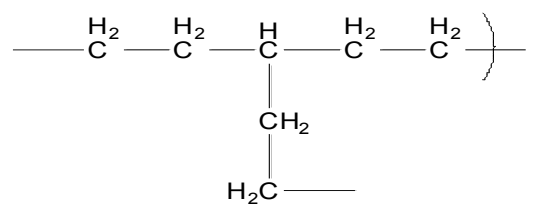

3.

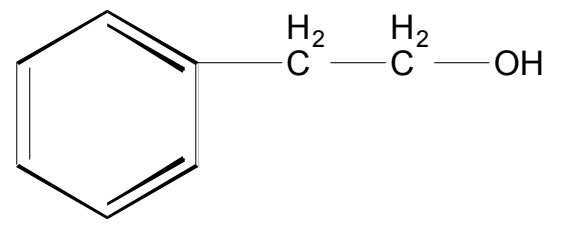

5.

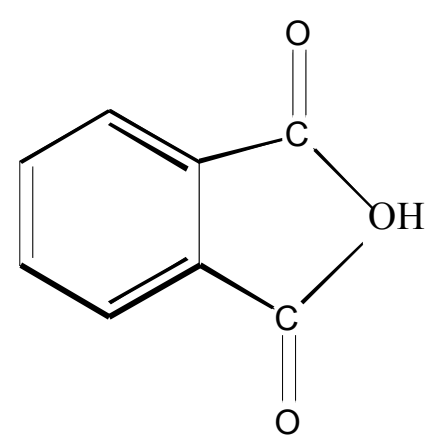

7.

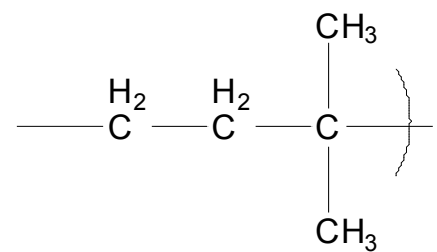

Fig. (11). The microstructures.
2.

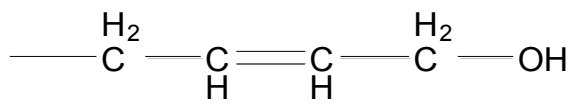

4.

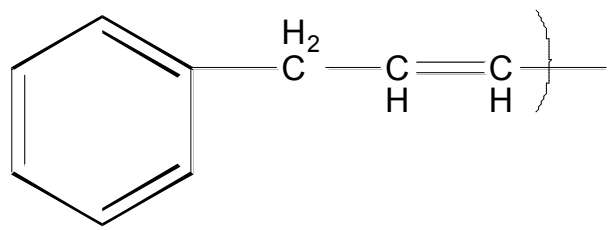

6.

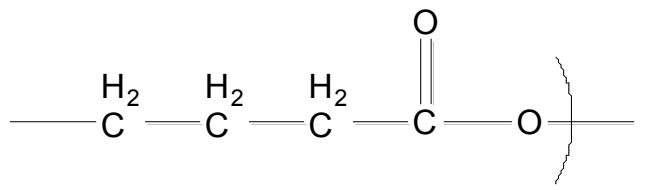




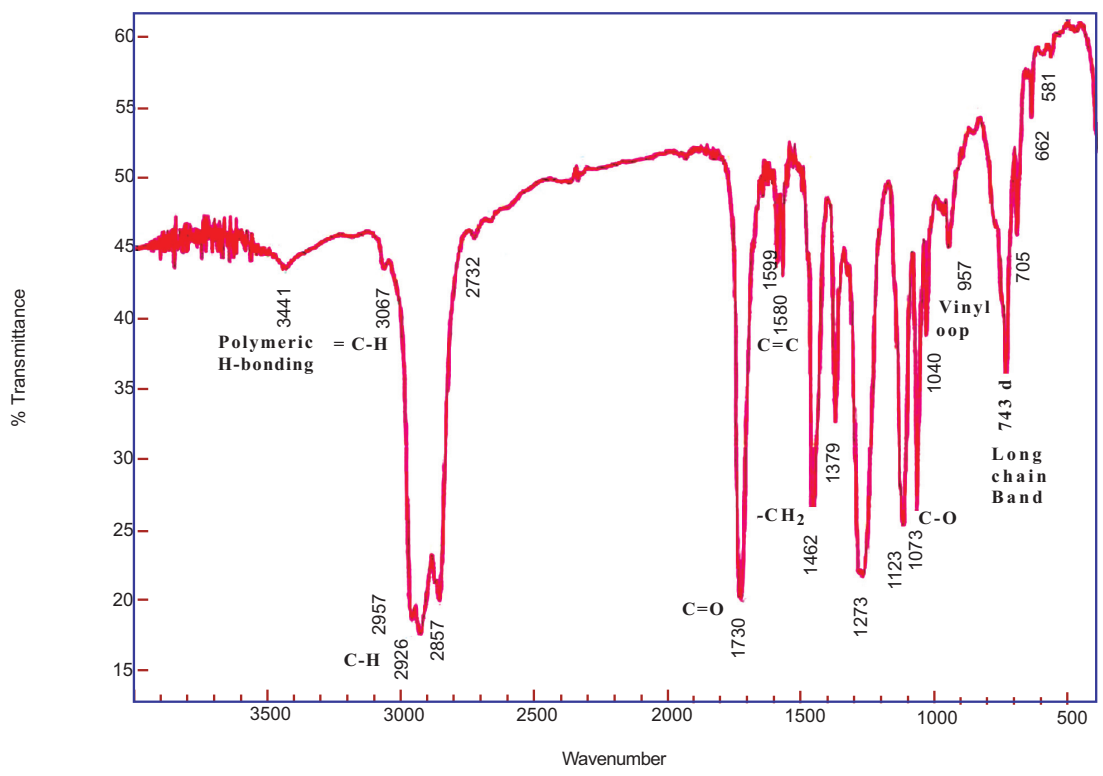

Fig. (12). FTIR spectra of the product.

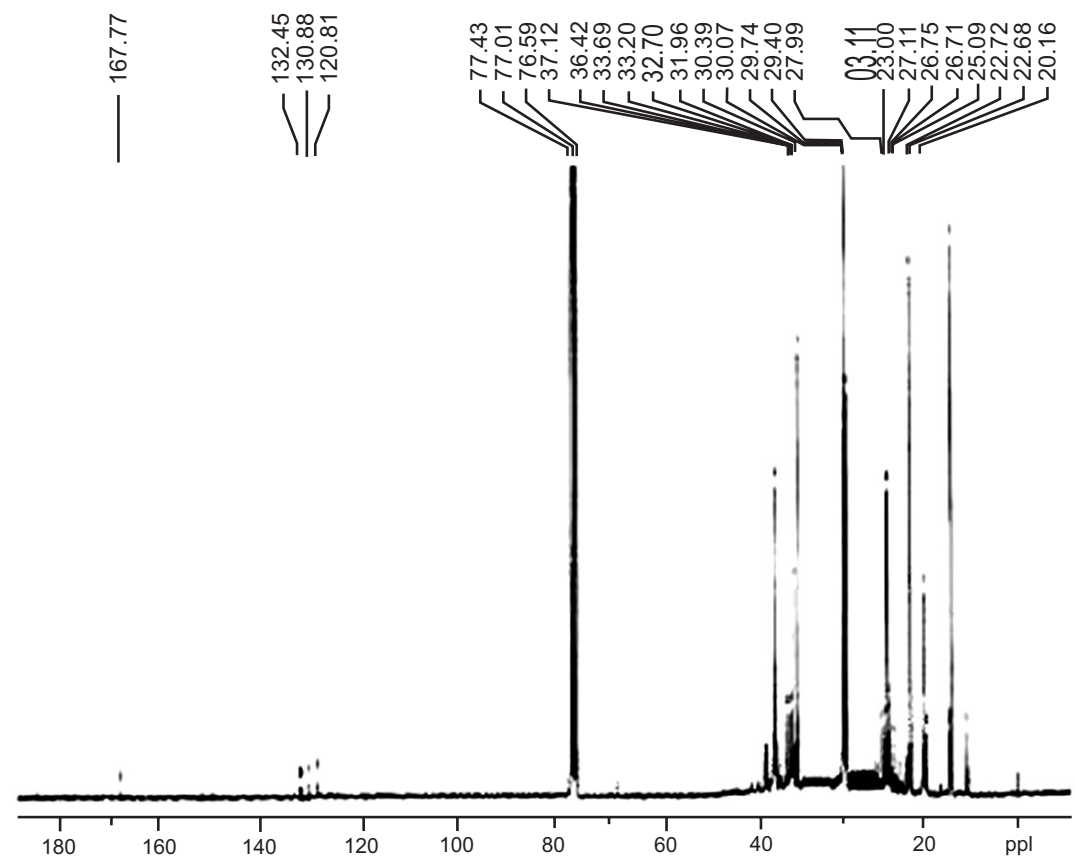

Fig. (13). $13 \mathrm{C}$-NMR spectra of the product.

I. Saturated hydrocarbon alkanes

II. Unsaturated polymeric alkenes with $\mathrm{OH}$ group and $\mathrm{C}=\mathrm{O}$ group

III. Aromatic carbonyl compounds

Characterization of Product Using Laser Light Scattering (LLS)

A commercial light-scattering spectrometer (ALV/SP150 equipped with an ALV-5000 multi-ô digital time correlator) was used with a solid-state laser (ADLAS DPY 425II, output power $400 \mathrm{~mW}$ at $\ddot{e}=532 \mathrm{~nm}$ ) as light source. The incident beam was vertically polarized with respect to the scattering plane. For static LLS, the instrument was calibrated with toluene to make sure that there has no angular dependence in the scattering angle of $20^{\circ}-150^{\circ}$ from toluene. The detail of the LLS instrumentation and theory can be found elsewhere [42-44]. All the measurements were carried out at $25+0.1{ }^{\circ} \mathrm{C}$. 
Table 4. Mass Spectrometric Analysis of the Products

\begin{tabular}{|c|c|c|c|c|c|c|c|c|c|}
\hline $\begin{array}{c}\text { Empirical } \\
\text { Formula }\end{array}$ & $\mathbf{M} / 2$ & $\begin{array}{c}\text { Empirical } \\
\text { Formula }\end{array}$ & $\mathbf{M} / 2$ & $\begin{array}{c}\text { Empirical } \\
\text { Formula }\end{array}$ & $\mathbf{M} / 2$ & $\begin{array}{c}\text { Empirical } \\
\text { Formula }\end{array}$ & $\mathbf{M} / 2$ & $\begin{array}{c}\text { Empirical } \\
\text { Formula }\end{array}$ & $\mathbf{M} / 2$ \\
\hline $\mathrm{C}_{8} \mathrm{H}_{5} \mathrm{O}_{3}^{+}$ & 149 & $\mathrm{C}_{3} \mathrm{H}_{7}^{+}$ & 43 & $\mathrm{C}_{11} \mathrm{H}_{23}{ }^{+}$ & 155 & $\mathrm{C}_{18} \mathrm{H}_{35} \mathrm{O}^{+}$ & 267 & $\mathrm{C}_{23} \mathrm{H}_{45} \mathrm{O}^{+}$ & 337 \\
\hline- & - & $\mathrm{C}_{4} \mathrm{H}_{9}$ & 57 & $\mathrm{C}_{12} \mathrm{H}_{24}{ }^{+}$ & 168 & - & - & - & - \\
\hline $\mathrm{C}_{8} \mathrm{H}_{4} \mathrm{O}_{2}^{+}$ & 132 & $\mathrm{C}_{6} \mathrm{H}_{13}{ }^{+}$ & 85 & $\mathrm{C}_{13} \mathrm{H}_{27}{ }^{+}$ & 183 & $\mathrm{C}_{19} \mathrm{H}_{37} \mathrm{O}^{+}$ & 281 & $\mathrm{C}_{24} \mathrm{H}_{47} \mathrm{O}^{+}$ & 351 \\
\hline $\mathrm{C}_{7} \mathrm{H}_{5} \mathrm{O}_{2}^{+}$ & 121 & $\mathrm{C}_{7} \mathrm{H}_{13}{ }^{+}$ & 97 & $\mathrm{C}_{14} \mathrm{H}_{29}{ }^{+}$ & 197 & $\mathrm{C}_{20} \mathrm{H}_{39} \mathrm{O}^{+}$ & 295 & $\mathrm{C}_{25} \mathrm{H}_{47} \mathrm{O}^{+}$ & 363 \\
\hline $\mathrm{C}_{8} \mathrm{H}_{10} \mathrm{O}^{+}$ & 122 & $\mathrm{C}_{8} \mathrm{H}_{15}{ }^{+}$ & 111 & $\mathrm{C}_{15} \mathrm{H}_{27}^{+}$ & 207 & $\mathrm{C}_{21} \mathrm{H}_{40} \mathrm{O}^{+}$ & 308 & $\mathrm{C}_{27} \mathrm{H}_{51} \mathrm{O}$ & 391 \\
\hline $\mathrm{C}_{7} \mathrm{H}_{4} \mathrm{O}^{+}$ & 104 & $\mathrm{C}_{9} \mathrm{H}_{17}{ }^{+}$ & 125 & $\mathrm{C}_{15} \mathrm{H}_{29} \mathrm{O}^{+}$ & 225 & - & - & - & - \\
\hline- & - & $\mathrm{C}_{10} \mathrm{H}_{21}$ & 141 & - & - & - & - & - & - \\
\hline- & - & - & - & $\mathrm{C}_{17} \mathrm{H}_{33} \mathrm{O}^{+}$ & 253 & $\mathrm{C}_{22} \mathrm{H}_{42} \mathrm{O}^{+}$ & 322 & - & - \\
\hline
\end{tabular}

The angular dependence of the excess absolute timeaveraged scattered intensity, known as the excess Rayleigh ratio, $R_{v v(q)}$, of a dilute polymer solution was measured. For a dilute polymer solution at a relatively low angle è, $R_{v v}(q)$ can be expressed as [45]:

$$
\frac{\mathrm{KC}}{\mathrm{R}_{\mathrm{vv}}(\mathrm{q})} \approx \frac{1}{\mathrm{M}_{\mathrm{w}}}\left(1+\frac{1}{3}<\mathrm{R}_{\mathrm{g}}^{2}>\mathrm{q}^{2}\right)+2 \mathrm{~A}_{2} \mathrm{C}
$$

where $K=4 \pi^{2} n^{2}(d n / d C)^{2} /\left(N_{A} \lambda_{0}^{4}\right) \quad$ and $\quad \mathrm{q}=\left(4 \pi \mathrm{n} / \lambda_{0}\right) \sin (\theta / 2)$ with NA, dn/dC, $n$ and ëo being Avogadro's number.

The specific refractive index increment, the solvent refractive index, and the wavelength of the light in vacuo, respectively. $\mathrm{M}_{\mathrm{w}}$ is the weight average molar mass; $\mathrm{A}_{2}$ is the second virial coefficient; and $\left.\left\langle\mathrm{Rg}_{\mathrm{g}}{ }^{2}\right\rangle_{\mathrm{Z}}{ }^{1 / 2}\right\rangle$ is the root-mean square z-average radius of gyration of the polymer chain. Refractive index increment of $(\sim 0.105 \mathrm{~mL} / \mathrm{g})$ for the polymer was measured by a high-precision differential refractometer [46], which enables us to measure $\mathrm{dn} / \mathrm{dC}$ and the scattered wavelength under identical experimental condition, so that the wavelength correction was eliminated. It is vital in static light scattering to have a precise value of differential refractive index increment. $\mathrm{dn} / \mathrm{dC}$, because the measured $\mathrm{M}_{\mathrm{w}}$ is proportional to $(\mathrm{dn} / \mathrm{dC})^{-2}$. The results of the experiment is presented in Table 5 and Fig. (14).
Fig. (14) shows a typical Zimm plot of catalyst samples in THF at $25{ }^{\circ} \mathrm{C}$, where a $0.50-\mu \mathrm{m}$ filter was used and $\mathrm{C}$ range from $2.00 \times 10^{-3}$ to $8.00 \times 10^{-3} \mathrm{~g} / \mathrm{mL}$. On the basis of equation 1 , we have calculated the values of $\mathrm{M}_{\mathrm{w}},\left\langle\mathrm{Rg}_{\mathrm{g}}\right\rangle$, and

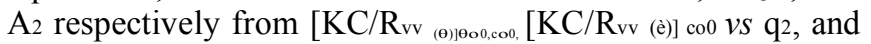
$\left[\mathrm{KC} / \mathrm{R}_{\mathrm{vv}}\right.$ (ө)]ео vs $\mathrm{C}$. The radius of gyration increases with the increase in molar mass. The positive values of $\mathrm{A}_{2}$ indicate that THF is reasonably good solvent for polymer under study at $25{ }^{\circ} \mathrm{C}$. The values of $\mathrm{A}_{2}$ decrease as the molar mass increases. This is understandable as the polymer chain increases then the solvent quality become poorer.

The GPC analysis of the products is presented in Table 6 . Studying Table $\mathbf{6}$ it could be inferred that the polydispersity is quite narrow of the butadiene products which is supported by variation in chain length.

\section{Kinetics of Butadiene Polymerization}

The kinetics scheme in polymerization process can handle anionic, cationic, and group transfer polymerization. We proposed here on the basis of our characterization results, the following polymerization scheme.

i Initiator Dissociation
ii Chain Initiation.

ii Chain Initiation.

Table 5. Summary of the Static Laser Light-Scattering (LLS) Results

\begin{tabular}{|c|c|c|c|}
\hline Catalyst Sample \#5 & $(\mathbf{M w}) \mathbf{1 0}-\mathbf{5}(\mathbf{g} / \mathbf{m o l})$ & $<\mathbf{R g}>(\mathbf{n m})$ & A2 104 $\left(\mathbf{m o l . m L} / \mathbf{g}^{2}\right)$ \\
\hline \hline Calcined at $1173 \mathrm{~K}$ & 7.15 & 75.00 & 2.76 \\
\hline Calcined at $873 \mathrm{~K}$ & 4.40 & 55.40 & 4.35 \\
\hline Calcined at $673 \mathrm{~K}$ & 2.52 & 36.15 & 6.50 \\
\hline
\end{tabular}

Table 6. GPC Analysis of the Product Stream

\begin{tabular}{|c|c|c|c|}
\hline Sample \#5 & Mw & Mn & Mw/Mn \\
\hline \hline Calcined at 1173K & 1454 & 1352 & 1.0757 \\
\hline Calcined at 873K & 1225 & 1210 & 1.0985 \\
\hline Calciend at 673K & 1180 & 1071 & 1.1010 \\
\hline
\end{tabular}




$$
\begin{aligned}
& \text { iii Propagation. } \\
& \text { iv Association. } \\
& \text { v Coupling (with the formation of chain growth } \\
& \text { intermediate). }
\end{aligned}
$$

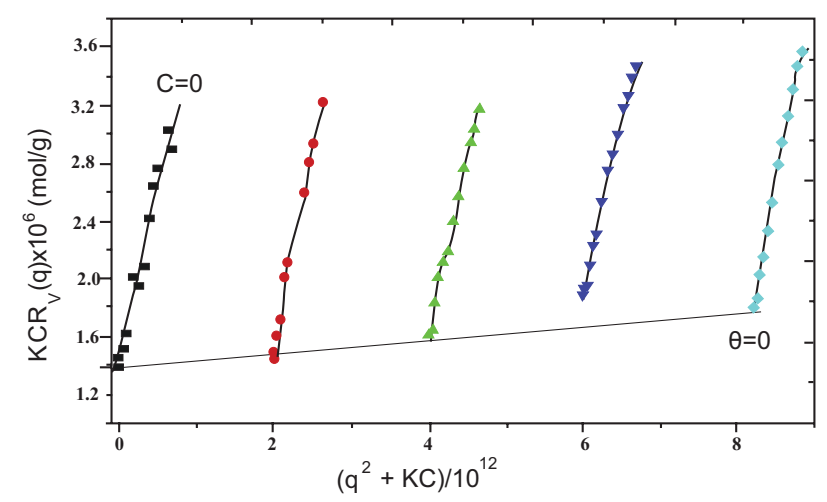

Fig. (14). Typical zimm plot for the sample 42 in $\mathrm{THF}$ at $25^{\circ} \mathrm{C}$, where the solution was clarified by $0.45 \mu \mathrm{m}$ filters and $\mathrm{C}$ ranged from $2.0 \times 10^{-3}$ to $8.00 \times 10^{-3} \mathrm{~g} / \mathrm{mL}$.

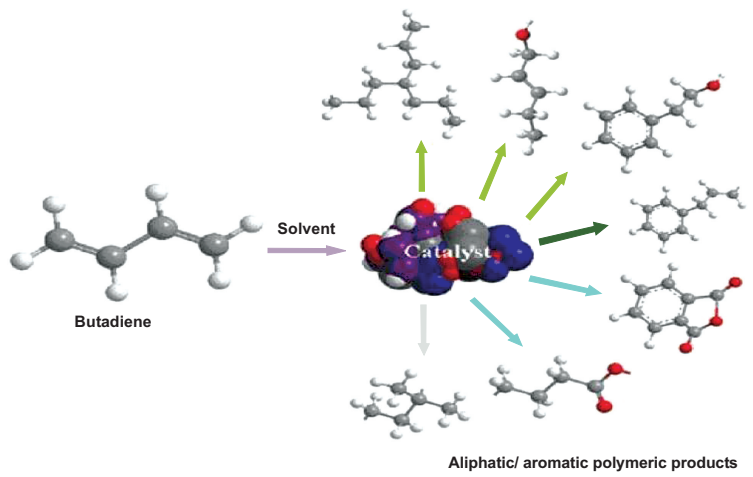

Fig. (15). The polymerization microstructures.

The whole polymerization process keeps track of different types of active sites. Once it is dissociated activation and initiation reactions, exchange reaction, chain transfer reaction and chain termination reaction proceeds. We assumed that the associated polymeric species exist as a dimmer when butadiene are attached to the catalyst active sites, electronic interaction comes into effect, thus modifying the overall geometry of the system. In this study we assume that there is only one type of propagating species i.e. only ion pair active catalyst sites generated due to different oxidation states of $\mathrm{Ni}$ and $\mathrm{Co}$.

Hsieh et al. [41, 42] has extensively studied the polymerization of styrene and butadiene in hydrocarbon solvent using different initiators and solvents. They have reported monomer reactivity ratios in various solvents. Their studies indicate that in polymerization, the reactivity ratios are a strong function of solvent and initiator. For styrene and butadiene the reactivity ratio for butadiene is about 50 times larger than reactivity ratio of styrene in cyclohexane solvent and of course with initiator. In the present study the polymerization reactivity has been achieved by just controlling the particle geometry in the bulk and on the surface which in turn control the equilibrium of the reaction. The percentages of polymer chain are associated in the dimeric nature of associated polymer. In the present study the control of this dimeric nature of chain propagation directs our reaction towards the formation of aliphatic and aromatic polymers. On the basis of the theory presented above and the FTIR, NMR and GPC, LLS, we postulated a scheme of catalytic reaction presented in Fig. (15), which indicates the interaction of different ionic/nonionic catalytic active sites and forms an intermediate which controls the product formation.

\section{CONCLUSIONS}

- The high surface area catalysts were active for the polymerization of Butadiene at low temperature and pressure.

- The calcinations temperature of the catalyst produces crystallinity and shifts it towards.

- the multiple phase transition i.e. responsible for the increase of active sites.

- $\quad$ No effect of pressure and temperature was observed on the product distribution.

- The catalyst active sites geometry and reaction conditions control, product selectivity.

- $\quad$ either towards the formation of aliphatic or aromatic compound.

- The characterization results indicate the formation of two types of intermediate, responsible for shifting the product selectivity towards aliphatic or aromatic polymers formation.

- The nature of acid catalytic active sites controls the catalytic reaction stochiometry.

- The polymerization product has very good polydispersity and high molecular weight.

- $\quad$ The $\mathrm{Ni}: \mathrm{Co}\left[\mathrm{O}_{x}\right]$ catalyst calcined at $1173 \mathrm{~K}$ showed higher activity and selectivity towards polymerization of butadiene in comparison with other catalysts samples in ethanol solvent.

\section{ACKNOWLEDGMENTS}

Higher Education Commission, Islamabad, Pakistan research grant no. $20-623 / \mathrm{R} \& \mathrm{D} / 2519$ is for this project gratefully acknowledged.

\section{REFERENCES}

[1] Boor, I.J. Ziegler Natta Catalysis and Polymerization, New York: Academic, 1979, p. 21.

[2] O'Connor, A.R.; White, P.S.; Brookhart, M. The mechanism of polymerization of butadiene by "ligand-free" nickel(II) complexes. J. Am. Chem. Soc., 2007, 129, 4142-4146.

[3] Saltman W.M. The Stereo Rubbers, Wiley-interscience, New York, 1977, p.211.

[4] Galvin, M.E.; Heffner, S.A. Reaction of butadiene with a heterogeneous Ziegler-Natta catalyst in solid polymers and solutions. Macromolecules. Macromolecules, 1989, 22, 3307-3311.

[5] Yu, G.; Li, Y.; Qu Y.; Li, X. Synthesis and characterization of polymer-supported lanthanide complexes and butadiene polymerization based on them. Macromolecules, 1993, 126, 67026707.

[6] Taube, R.; Sylvester, G. Applied Homogeneous Catalysis with Organometallic Compounds, VCH: Weinheim, 1996, p. 280.

[7] Monteil, V.; Spitz, R.; Boisson, C. Polymerization of butadiene and 
copolymerization of butadiene with styrene using neodymium amide catalysts. Polym. Int., 2004, 53, 576-581.

[8] Barbotin, F.; Spitz, R.; Boisson, C. Polymerization of butadiene with a new catalyst based on a neodymium amide precursor. Macromol. Chem. Phys., 1999, 200, 1163-1168.

[9] Wilson, D.J. Polymerization of 1,3-butadiene using aluminoxanebased Nd-carboxylate catalysts. Polym. Int., 1996, 39, 235-241.

[10] Mihir, M.P.; Malav, A.K.; Jayantilal, D.J. Thermal and catalytic aspects of Ln(III) polymer-metal complexes. Polym. Int. 2009, 58, 728-731.

[11] Duvakina, N.V.; Monakov, Y.B. Unusual influence of the preparation conditions of neodymium-magnesium catalyst systems on their stereospecificity in butadiene polymerization. Dokl. Chem., 2002, 384, 129-132.

[12] Dong, W.; Masuda, T. Novel neodymium (III) isopropoxidemethylaluminoxane catalyst for isoprene polymerization. J. Polym. Sci. Pol. Chem., 2002, 40, 1838-1842.

[13] Dong, W.; Masuda, T. Homogeneous neodymium isopropoxide/modified methylaluminoxane catalyst for isoprene polymerization. Polymer, 2003, 44, 1561-1566.

[14] Mello, I.L.; Coutinho, F.M.B.; Nunes, D.S.S.; Soares, B.G.; Costa, M.A.S.; de Santa Maria L.C. Solvent effect in cis-1,4 polymerization of 1,3-butadiene by a catalyst based on neodymium. Eur. Polym. J., 2004, 40, 635-642.

[15] Taniguchi, Y.; Dong, W.; Katsumata, T.; Shiotsuki, M.; Masuda, T. Novel neodymium-based ternary catalyst, $\mathrm{Nd}(\mathrm{O} i$ $\mathrm{Pr}_{3} /\left[\mathrm{HNMe}_{2} \mathrm{Ph}\right]^{+}\left[\mathrm{B}\left(\mathrm{C}_{6} \mathrm{~F}_{5}\right)_{4}\right]^{-} / i-\mathrm{Bu} \mathrm{u}_{3} \mathrm{Al}$, for isoprene polymerization. Polym. Bull., 2005, 54, 173-178.

[16] Sarasua, J.R.; Rodríguez, N.L.; Arraiza, A.L.; Meaurio, E. Stereoselective crystallization and specific interactions in polylactides. Macromolecules, 2005, 38, 8362-8365.

[17] Ricci, G.; Boffa, G.; Porri, L. Polymerization of 1,3-dialkenes with neodymium catalysts. Some remarks on the influence of the solvent. Makromol. Chem., Rapid. Commun., 1986, 7, 355-60.

[18] Hlatky, G.G. Heterogeneous single-site catalysts for olefin polymerization. Chem. Rev., 2004, 100, 1347-1352.

[19] Thomas, J.M.; Richard, C.; Catlow, A.; Sankar, G. Determining the structure of active sites, transition states and intermediates in heterogeneously catalysed reactions. Chem. Commun. 2002, 24, 2921-2925.

[20] Song, I.K.; Young, L.W. Heteropolyacid (HPA)-polymer composite films as heterogeneous catalysts and catalytic membranes. Appl. Catal. A-Gen., 2003, 256, 77-98.

[21] Bianchini, D.; Bichinho, K.M.; dos Santos, J.H.Z. Polyethylenes produced with zirconocene immobilized on MAO-modified silicas. Polymer, 2002, 43, 2937-2943.

[22] Denis, V.S.; Vladimir, A.Z.; Alexander, G.P.; Gennady, D.B. Supported Ziegler-Natta catalysts for propylene polymerization. Study of surface species formed at interaction of electron donors and $\mathrm{TiCl}_{4}$ with activated $\mathrm{MgCl}_{2}$. 2009, (In press).

[23] Grieken, R.V.; Calleja, G.; Serrano, D.; Martos, C.; Melgares, A.; Saurez, I.; The role of the hydroxyl groups on the silica surface when supporting metallocene/MAO catalysts. Polym. React. Eng., 2003, 11, 17-22.

[24] Minhas, R.K.; Scoles, L.; Wong, S.; Gambarotta, S. Tri- and tetravalent titanium alkyls supported by organic amides. Organometallics, 1996, 15, 1113-1118.

[25] Knoke, S.; Chem, D.; Ferrari, D.; Tesche, B.; Fink, G. Microkinetic videomicroscopic analysis of olefin polymerization with a supported metallocene. Catal. Commun., 2003, 42, 5090-5093.

[26] Xu, R.W.; Liu, D.B.; Wang, S.B.; Mao, B.Q. Preparation of spherical $\mathrm{MgCl}_{2}$-supported late-transition metal catalysts for ethylene polymerization. Macromol. Chem. Phys., 2006, 207, 779783.

[27] Billmeyer, F.W. Jr.; Ed. $3^{\text {rd }}$ ed. Polymer Science, WileyInterscience, 1984, p. 96.

[28] Huang, R.; Liu, D.; Wang, S.; Mao, B. Spherical $\mathrm{MgCl}_{2}$ supported iron catalyst for ethylene polymerization: effect of the preparation procedure on catalyst activity and the morphology of polyethylene particles. Macromol. Chem. Phys., 2004, 205, 966-968.

[29] Takehira, K.; Shishido, T.; Wang, P.; Kosaka, T.; Takaki, K. Autothermal reforming of $\mathrm{CH}_{4}$ over supported $\mathrm{Ni}$ catalysts prepared from $\mathrm{Mg}-\mathrm{Al}$ hydrotalcite-like anionic clay. J. Catal., 2004, 221, 43-46.

[30] Narayan, R.V.; Kanniah, V.; Dhathathreyan, A. Tuning size and catalytic activity of nano-clusters of cobalt oxide. J. Chem. Sci. 2006, 118,179-181.

[31] Jin, S. H.; Kim, S. H.; Cho, H. N.; Choi, S.K. Synthesis and characterization of side-chain liquid-crystalline polymers containing a poly(1,6-heptadiyne) derivative. Macromolecules, 1991, 24, 6050-6055.

[32] Huang, Y.J.; Qi, G.R.; Chen, L.S. Effects of morphology and composition on catalytic performance of double metal cyanide complex catalyst. Appl. Catal. A-Gen., 2003, 240, 263-265.

[33] Serra, M.; Salagre, P.; Cesteros, Y.; Medina, F.; Sueiras, J.E. Study of preparation conditions of $\mathrm{NiO}-\mathrm{MgO}$ systems to control the morphology and particle size of the NiO phase, Solid State Ionics, 2000, 134, 229-231.

[34] Cesteros, Y.; Salagre, P.; Medina, F.; Sueiras, J.E. Synthesis and characterization of several $\mathrm{Ni} / \mathrm{NiAl}_{2} \mathrm{O}_{4}$ catalysts active for the 1,2,4-trichlorobenzene hydrodechlorination. Appl. Catal. BEnviron., 2000, 25, 213-215.

[35] Kowalski, G.; Pielichowski, J.; Jasieniak, M. Polymer supported cobalt(II) catalysts for alkene epoxidation. Appl. Catal., 2003, 247 , 295-302.

[36] Penczek, S.; Polym, J. Terminology of kinetics, thermodynamics, and mechanisms of polymerization. Sci. Pol. Chem., 2002, 40, $1665-1668$.

[37] Krajewski-Bertrand, M.; Laupretre, F. ${ }^{13} \mathrm{C}$ NMR investigation of the size of the moving units in polybutadienes of various microstructures macromolecules. Macromolecules, 1996, 29, 76167618.

[38] Brandolini A.J.; Hills, D.D. NMR Spectra of Polymers and Polymer Additives, Marcel Dekker: New York, 2000, pp. 123-127.

[39] Gilbert, R.G.; Napper, D.H. The direct determination of kinetic parameters in emulsion polymerization systems. Polym. Rev. 1983, $23,127$.

[40] Grisi, F.; Longo, L.; Zambelli, A.; John, A.E. Group 4 Cs symmetric catalysts and 1-olefin polymerization. J. Mol. Catal., 1999, 140, 225-233.

[41] Lee, J.H.; Liu, S.T. Ethylene polymerization catalyzed by diiminepalladium(II) complexes modified on silicas. J. Chin. Chem. Soc. 2006, 53, 1349-1354.

[42] Hsieh, H.L.; Quirk, R.P. Anionic Polymerization: Principle and Practice, Marcel Dekker: New York, 1996, pp. 321-324.

[43] Pecora, R.; Berne, J. Dynamic light Scattering. Plenum Press: New York, 1976, pp. 551-561.

[44] Chu, B. Laser Light Scattering, $2^{\text {nd }}$ ed., Academic Press: New York, 1991, pp. 788-791

[45] Zimm, B.H. Apparatus and methods for measurement and interpretation of the angular variation of light scattering; preliminary results on polystyrene solutions. J. Chem. Phys., 1948, 16, 1099-1101

[46] Wu, C.; Xia, K.Q. Incorporation of a differential refractometer into a laser light-scattering spectrometer. Rev. Sci. Instrum., 1994, 65, 587-590.

[47] Toshima, N.; Hirakawa, K. Polymer-protected Pt/Ru bimetallic cluster catalysts for visible-light-induced hydrogen generation from water and electron transfer dynamics. Appl. Surf. Sci., 1997, 121, 534-537.

[48] Dong, H. B.; Xu, Y.Y.; Yi, Z.; Shi J.L. Modification of polysulfone membranes via surface-initiated atom transfer radical polymerization. Appl. Surf. Sci., 2009, 255, 6860-6868. 